\title{
Efficient Minimax Design of Networks without Using Derivatives
}

\author{
Madsen, Kaj; Nielsen, Niels Ole; Schjær-Jacobsen, Hans; Thrane, L.
}

Published in:

I E E E Transactions on Microwave Theory and Techniques

Link to article, DOI:

10.1109/TMTT.1975.1128686

Publication date:

1975

Document Version

Publisher's PDF, also known as Version of record

Link back to DTU Orbit

Citation (APA):

Madsen, K., Nielsen, N. O., Schjær-Jacobsen, H., \& Thrane, L. (1975). Efficient Minimax Design of Networks without Using Derivatives. I E E E Transactions on Microwave Theory and Techniques, 23(10), 803-809. https://doi.org/10.1109/TMTT.1975.1128686

\section{General rights}

Copyright and moral rights for the publications made accessible in the public portal are retained by the authors and/or other copyright owners and it is a condition of accessing publications that users recognise and abide by the legal requirements associated with these rights.

- Users may download and print one copy of any publication from the public portal for the purpose of private study or research.

- You may not further distribute the material or use it for any profit-making activity or commercial gain

- You may freely distribute the URL identifying the publication in the public portal 


\title{
Efficient Minimax Design of Networks without Using Derivatives
}

\author{
KAJ MADSEN, OLE NIELSEN, STUDENT MEMBER, IEEE, \\ HANS SCHJ FR-JACOBSEN, STUDENT MEMBER, IEEE, AND \\ LARS THRANE, STUDENT MEMBER, IEET
}

\begin{abstract}
A new minimax network optimization algorithm not requiring derivatives has been developed. It is based on successive linear approximations to the nonlinear functions defining the problem. Adequate modeling of distributed parameter circuits for optimization purposes often involves parasitics, etc., which makes the gradient computation by the adjoint network method or related methods rather complicated, and often numerical errors are introduced in the gradients. Consequently, the algorithm is found to be of particular relevance in optimum design of practical microwave networks. The relative advantages of the proposed algorithm are established by comparison with known gradient and nongradient algorithms based on optimization of cascaded transmission-line transformers. The relevance to microwave filter design is demonstrated by an example which represents an improvement of analytical filter design results. Finally, optimum broad-band design of a practical coaxial transferred-electron reflection-type amplifier is carried out by means of the proposed method. The results are supported by experimental verification.
\end{abstract}

\section{INTRODUCTION}

$\mathbf{I}$ N A RECENT panel discussion [1], it was generally agreed that even if a number of automated optimization algorithms have been published during the past years, only a few examples of practical use to real microwave circuit design problems have appeared in the literature. This is particularly true when methods that make use of objective function derivatives are considered. We think that one of the reasons for this is that although very efficient methods for gradient computations have been developed [2], these methods are not easily implemented for microwave circuits described by distributed parameters for the following reasons. When adequately modeling a microwave circuit for optimization purposes, parasitics and junction effects must be taken into account in order to establish correlation with measured.performance at a later stage of the design process. However, such effects most often have to be included in the circuit model by tabulated data eventually represented by function approximations. One is therefore well motivated to try to develop efficient and reliable optimization methods that do not require derivatives.

Early attempts to develop nongradient optimization procedures, of which some examples may be found in [3]-[8], have mainly been based on modifications of

Manuscript received November 27, 1974; revised May 14, 1975. K. Madsen is with the Institute for Numerical Analysis, Technical University of Denmark, DK-2800 Lyngby, Denmark.

$O$. Nielsen, H. Schjær-Jacobsen, and L. Thrane are with the Electromagnetics Institute, Technical University of Denmark, DK-2800 Lyngby, Denmark. single-parameter optimization schemes in conjunction with standard objective function definitions. A relatively small amount of work has been done to establish the individual advantages of different approaches, and since the advent of the adjoint network method [9] attention has been focused on the development and testing of efficient gradient methods, notably by Bandler and his co-workers $[10]-[12]$ and others $[13]-[16]$.

The purpose of this paper is to present a new minimax optimization algorithm that does not require derivatives and to report on its application to realistic design of practical microwave networks. The new approach is based on successive linear approximations to the nonlinear equations defining the optimization problem. The approximating linear systems are solved in the minimex sense with automatically adjusted bounds on the solutions, thereby creating a sequence of response functions that will eventually converge to the optimum response specified by the designer. In presenting a new algorithm, we find it indispensible that its performance is related to results obtained by other workers, and this is done by considering both gradient and nongradient algorithms.

\section{THE NEW ALGORITHM}

\section{A. Mathematical Description}

The present method for nonlinear minimax optimization uses derivative approximations which are updated by a rank-one updating formula rather than exact derivatives [16].

The problem is that of minimizing

$$
F^{\prime}(x)=\max _{j}\left|f_{j}(x)\right|
$$

where

$$
f_{j}(\boldsymbol{x})=f_{3}\left(x_{1}, \cdots, x_{n}\right), \quad j=1, \cdots, m
$$

is a set of residuals which are nonlinear functions of the design parameters $x$. In the iteration we find sn increment $h_{k}$ to add to the approximate solution $x_{k}$, and the next iterand $\boldsymbol{x}_{k+1}$ is either $\boldsymbol{x}_{k}$ or $\boldsymbol{x}_{k}+\boldsymbol{h}_{k}$. Now the approximate derivative matrix at the point $\boldsymbol{x}_{k+1}, \overline{\boldsymbol{B}}_{k+1}$ is found by the Broyden updating formula [17]

$$
\overline{\boldsymbol{B}}_{k+1}=\overline{\boldsymbol{B}}_{k}+\frac{\left(\boldsymbol{f}\left(\boldsymbol{x}_{k}+\boldsymbol{h}_{k}\right)-\boldsymbol{f}\left(\boldsymbol{x}_{k}\right)-\overline{\boldsymbol{B}}_{i} \boldsymbol{h}_{k}\right) \boldsymbol{h}_{k}^{T}}{\boldsymbol{h}_{k}^{T} \boldsymbol{h}_{k}}
$$

where $f(x)=\left(f_{1}(x), \cdots, f_{m}(x)\right)$. (Note that this formula 
requires no extra calculations of function values.) The initial approximation $\overline{\boldsymbol{B}}_{0}$ is found by a difference approximation

$$
b_{j \imath}{ }^{(0)}=\frac{f_{j}\left(x_{0}+t e_{i}\right)-f_{j}\left(x_{0}\right)}{t}
$$

where $t$ is a small positive number, and $e_{i}$ is the $i$ th coordinate vector.

In order that the matrices $\overline{\boldsymbol{B}}_{k}$ are good approximations to the derivative matrices at $\boldsymbol{x}_{k}, k=1,2, \cdots$, it is important that the directions $h_{k}$ satisfy some linear independence condition. This is ensured by letting every third iteration be a "special iteration" in which $\boldsymbol{h}_{k}$ is chosen such that for every $3 n$ consecutive directions, $h_{p+1}, \cdots, h_{p+3 n}$, there is a subset which is a basis for the vector space $R^{n}$. This method is due to Powell [18].

The "normal iterations" of the algorithm go as follows. Let $F_{k}(\boldsymbol{h})$ be defined through

$$
\boldsymbol{F}_{k}(\boldsymbol{h})=\left\|\boldsymbol{f}\left(\boldsymbol{x}_{k}\right)+\overline{\boldsymbol{B}}_{k} \boldsymbol{h}\right\|
$$

where the norm is

$$
\|y\|=\max _{1 \leq j \leq m}\left|y_{j}\right| .
$$

Then $h_{k}$ is found as solution to the linear problem

$$
\boldsymbol{F}_{k}\left(\boldsymbol{h}_{k}\right)=\min _{\|\boldsymbol{h}\| \leq \lambda_{k}}\left\{\boldsymbol{F}_{k}(\boldsymbol{h})\right\} \text {. }
$$

This subproblem may be solved by a standard linear programming routine, but it is solved more efficiently by a method which is similar to the exchange algorithm [19].

The point $\left(\boldsymbol{x}_{k}+\boldsymbol{h}_{k}\right)$ is chosen as the next point in the iteration if the decrease in the objective function $F$ is satisfactory compared to the decrease in the linear approximation $F_{k}$, more precisely, if

$$
\Delta_{k} F \geq 0.01 \Delta_{k} F_{k}
$$

where

$$
\Delta_{k} F=\boldsymbol{F}\left(\boldsymbol{x}_{k}\right)-\boldsymbol{F}\left(\boldsymbol{x}_{k}+\boldsymbol{h}_{k}\right)
$$

and

$$
\Delta_{k} F_{k}=F_{k}(0)-F_{k}\left(h_{k}\right) .
$$

If (7) fails, we let $x_{k+1}=x_{k}$

The bound $\lambda_{k+1}$ is found as follows. If

$$
\Delta_{k} F \leq 0.1 \Delta_{k} F_{k}
$$

then we let

$$
\lambda_{k+1}=0.7\left\|h_{k}\right\| .
$$

As a consequence of this the bound will decrease when $x_{k+1}=x_{k}$, and this ensures that the iteration cannot stop at a point which is not a local minimum of $F$. If (11) fails, and

$$
\Delta_{k}^{2} F_{k} \leq \frac{1}{2} \Delta_{k} F
$$

where

$$
\Delta_{k}^{2} F_{k}=\left\|f\left(x_{k}+h_{k}\right)-\left\{f\left(x_{k}\right)+\bar{B}_{k} h_{k}\right\}\right\|
$$

then we choose $\lambda_{k+1}=\min \left\{\Lambda, \max \left(\lambda_{k}, 2\left\|\boldsymbol{h}_{k}\right\|\right)\right\}$ where $\Lambda>0$ is a general upper bound on the step length. If neither (11) nor (13) is satisfied, we let $\lambda_{k+1}=\left\|h_{k}\right\|$. The choice of constants in formulas (11)-(13) is based on our experience with the algorithm.

In the special iterations, the directions $h_{k}$ are found as in [18] and the step length is $\lambda_{k} . h_{k}$ is a multiple of the first row in an orthogonal $n \times n$ matrix $\bar{D}_{k}$ which has the property that the space spanned by the last $j$ rows in $\bar{D}_{k}$ is the same as the space spanned by the first $s$ elements in the sequence $\boldsymbol{h}_{k-1}, \boldsymbol{h}_{k-2}, \cdots, s$ being chosen as small as possible. In these iterations $\lambda_{k+1}=\lambda_{k}$, and $x_{k+1}=x_{k}$ unless

$$
F\left(\boldsymbol{x}_{k}+\boldsymbol{h}_{k}\right)<F\left(\boldsymbol{x}_{k}\right)
$$

in which case $x_{k+1}=x_{k}+h_{k}$.

For the sake of clarity, a flow diagram of the algorithm is shown in Fig. 1.

In [20] it is shown that the method has sure convergence properties, and also that if the problem under consideration is nonsingular, then the final rate of convergence is superlinear.

\section{B. Practical Implementation}

The proposed algorithm has been implemented for a digital computer (IBM 370/165) in double precision

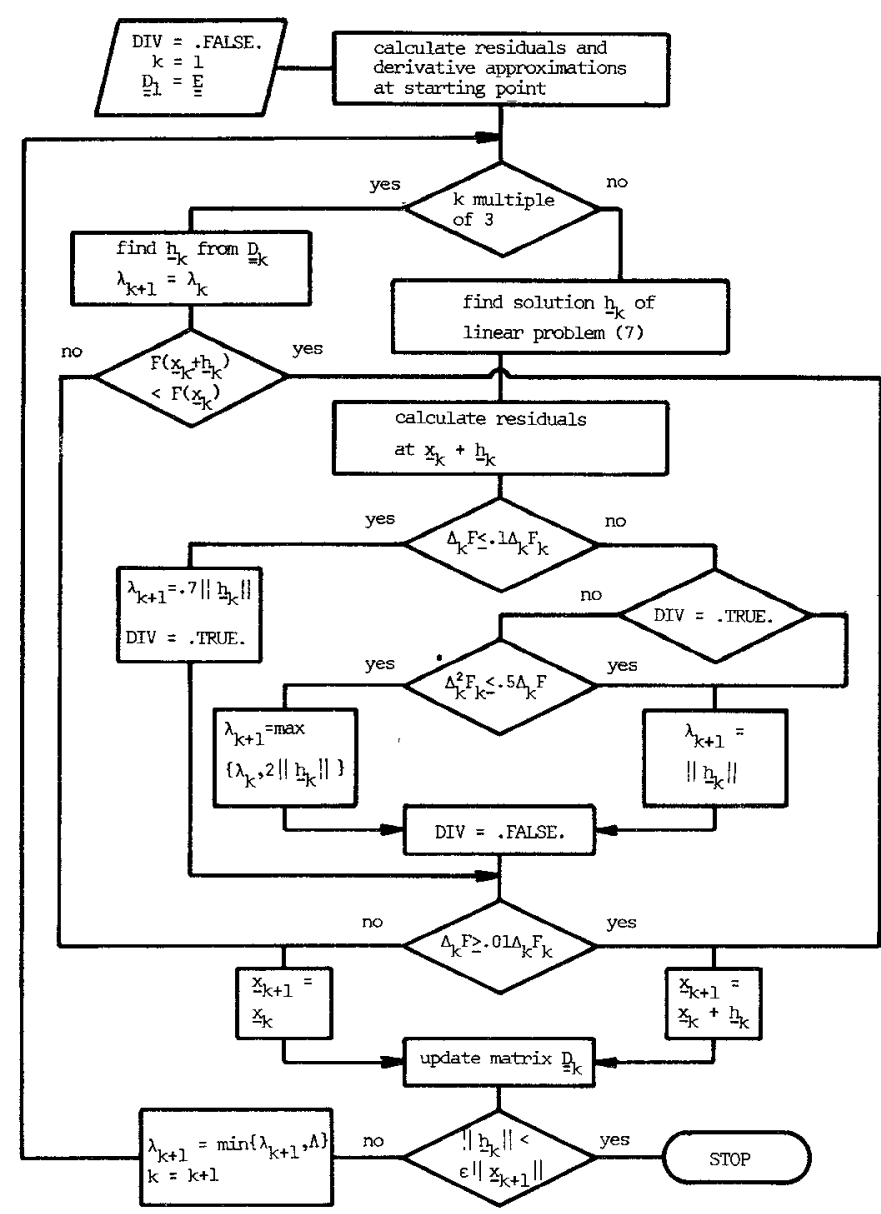

Fig. 1. Simplified mathematical flow diagram of minimax algorithm. (Variables with a single underbar are boldface italic in text. Variables with double underbars are boldface italic with an overbar in text.) 
Fortran IV. ${ }^{1}$ The subroutine is very easy to apply. The user needs to program a subroutine for calculating the residuals $f_{j}(x)$, and to provide initial values $x_{0}$ for the sequence of vectors and $\lambda_{0}$ for the sequence of bounds; further, the upper bound $\Lambda$ for the step length and the value of $t$ in formula (4) must be chosen.

$\Lambda$ should not be chosen too large, since this might cause bad derivative approximations during the iteration. The more variables $x_{i}$, the smaller $\Lambda$ should be chosen. $\lambda_{0}$ must not be greater than $\Lambda$; normally $\Lambda$ is equal to $\lambda_{0}$ or a small multiple of $\lambda_{0}$. In all examples to follow we have used $\Lambda=2 \lambda_{0}$ and $\lambda_{0}=0.1$. The value of $t$ is not critical. We have used $t=10^{-3}$, and also tried $t=10^{-6}$, which gave no difference at all.

The program package is available from the authors on request.

\section{COMPARISON WITH KNOWN ALGORITHMS}

The proposed nongradient algorithm is compared with known algorithms on the basis of optimization of twoand three-section cascaded transmission-line 10:1 transformers (Fig. 2) over a 100-percent bandwidth [6]. The residuals have been defined as

$$
f_{j}(x)=\frac{1}{2}\left|\rho_{j}(x)\right|^{2}, \quad j=1,2, \cdots, 11
$$

where $\rho_{j}$ is the complex reflection coefficient at the $j$ th sample frequency with the eleven normalized sample frequencies being given as $(0.5,0.6,0.7,0.77,0.9,1.0,1.1$, $1.23,1.3,1.4,1.5)$ in the three-section case and being equidistantly spaced in the two-section case. The basis of algorithm comparisons will be the total number of transformer response evaluations required to bring the maximum reflection coefficient

$$
\max _{j}\left|\rho_{j}\right|
$$

within 0.01 percent of its optimum value in the two-section case and within five correct digits in the three-section case.

In Fig. 3(a) -(d) the value of (17) is depicted as a function of the number of network response evaluations $N$ for the two-section quarter-wave transformer with different starting points. Also shown are the corresponding curves for the gradient algorithm presented by Madsen et al. [16].

In Table I comparisons are made with previously published algorithms. It should be pointed out here that the number of network evaluations required by the gradient methods includes evaluation of the gradients by the adjoint network method. If, however, the adjoint network method is not feasible, numerical differentiation has to be carried out in each step. This point is demonstrated by the entry in Table I showing results for a gradient algorithm [16] when (4) is applied for the derivatives instead of the adjoint network method. The results from 'Table I indicate that the new method is significantly faster than

\footnotetext{
1 Although double precision is not necessary for any of the examples presented, we use it because the difference in computing time between single and double precision on the IBM 370 is negligible.
}

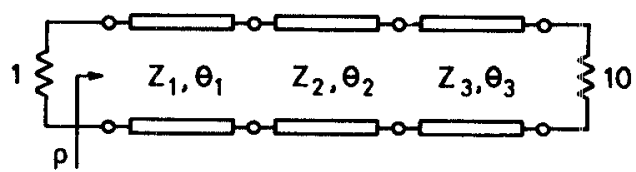

Fig. 2. Three-section cascaded transmission-line 10:1 transformer. Characteristic impedances $Z$ and electrical lengths $\theta$ (radians at center frequency).

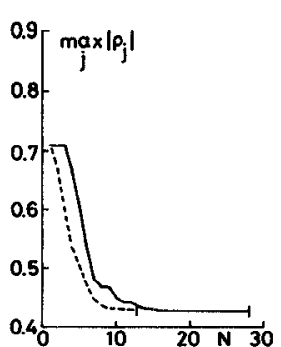

(a)

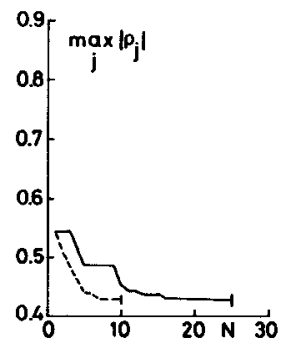

(c)

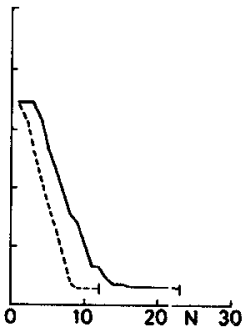

(b)

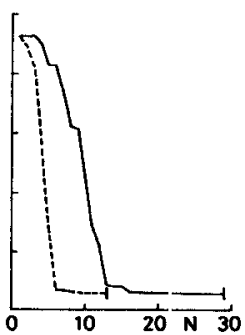

(d)
Fig. 3. Reduction in maximum reflection coefficient for a twosection 10:1 quarter-wave transformer with 100-percent bandwidth optimized to 0.01 -percent accuracy. [16]. - new method. Starting points $\left(\dot{Z}_{1}, Z_{2}\right)$ : (a) $(1.0,3.0)$; (b) $(1.0,6.0)$; (c) $(3.5,6.0)$; (d) $(3.5,3.0)$.

TABLE I

Optimization to 0.01-Percent Accuracy of a Two-Section 10:1

\begin{tabular}{|c|c|c|c|c|}
\hline $\begin{array}{l}\text { Starting Values } \\
Z_{1} \\
Z_{2}\end{array}$ & $\begin{array}{r}1.0 \\
3.0\end{array}$ & $\begin{array}{l}1.0 \\
6.0\end{array}$ & $\begin{array}{l}3.5 \\
6.0\end{array}$ & $\begin{array}{l}3.5 \\
3.0\end{array}$ \\
\hline & \multicolumn{4}{|c|}{ Number of Network Evaluations } \\
\hline $\begin{array}{l}\text { Gradient Methods } \\
\text { Grazor [10] }\end{array}$ & 126 & 83 & 52 & 29 \\
\hline Least $p$ th [11] $(p=100)$ & $\begin{array}{r}120 \\
22\end{array}$ & 30 & 15 & 14 \\
\hline Madsen et al. $[16]$ & 13 & 12 & 10 & 13 \\
\hline $\begin{array}{l}\text { Same, but with numerieal } \\
\text { differentiation }\end{array}$ & 37 & 34 & 28 & 37 \\
\hline Nongradient Methods & & & & \\
\hline Razor [6] & $\left\{\begin{array}{l}157 \\
207\end{array}\right.$ & $\left\{\begin{array}{r}34 \\
152\end{array}\right.$ & $\left\{\begin{array}{l}223 \\
100\end{array}\right.$ & $\left\{\begin{array}{l}210 \\
163\end{array}\right.$ \\
\hline New algorithm & 28 & 23 & 25 & 29 \\
\hline
\end{tabular}
Quarter-Wave Transformer with 100-Percent Bandwidth

the other direct method compared with, namely, razor [6]. It further compares favorably with the gradient methods.

In Fig. 4 and Table II, left column, results are quoted for the three-section quarter-wave transformer. Table II, right columns, give the corresponding results when both impedances and lengths are varied. Again, the new algorithm is superior compared to the razor search strategy. Among the gradient algorithms, the least $p$ th objective $[12]$, in conjunction with the Fletcher variable metric algorithm [14], still possesses the fastest convergence on the only two test cases for which results are available. 


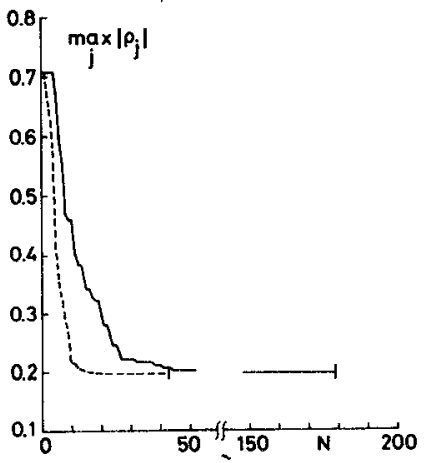

Fig. 4. Reduction in maximum reflection coefficient for a threesection 10:1 quarter-wave transformer with 100-percent bandwidth optimized to 0.01 -percent accuracy. _ _ gradient method [16]. - new method. Starting point $\left(Z_{1}, Z_{2}, Z_{3}\right):(1.0,3.16228$, 10.0)

TABLE II

Optimization to Five Correct Digits of a Three-Section 10:1 Transformer with 100-Percent Bandwidth

\begin{tabular}{|c|c|c|c|}
\hline \multirow[b]{2}{*}{$\begin{array}{l}\text { Starting Values } \\
Z_{1} \\
\theta_{1} \\
Z_{2} \\
\theta_{2} \\
Z_{3} \\
\theta_{3}\end{array}$} & \multirow{2}{*}{$\begin{array}{c}\begin{array}{c}\text { Fixed } \\
\text { Lengths }\end{array} \\
\\
\\
1.0 \\
\pi / 2 \\
3.16228 \\
\pi / 2 \\
10.0 \\
\pi / 2\end{array}$} & \multicolumn{2}{|c|}{$\begin{array}{l}\text { Variable Lengths } \\
\text { and Impedances }\end{array}$} \\
\hline & & $\begin{array}{c}1.0 \\
\pi / 2 \\
3.16228 \\
\pi / 2 \\
10.0 \\
\pi / 2\end{array}$ & $\begin{array}{l}1.5 \\
0.8 \cdot \pi / 2 \\
3.0 \\
1.2 \cdot \pi / 2 \\
6.0 \\
0.8 \cdot \pi / 2\end{array}$ \\
\hline $\begin{array}{l}\text { Gradient Methods } \\
\text { Osborne-Watson [10], [15] } \\
\text { Grazor [10] } \\
\text { Least } p \text { th [12] } \\
\text { (Average values) } \\
\text { Madsen et al. }[16]\end{array}$ & Number 0 & $\begin{array}{l}860^{a} \\
696 \\
155\end{array}$ & $\begin{array}{l}237^{\circ} \\
498 \\
95\end{array}$ \\
\hline $\begin{array}{l}\text { Nongradient Methods } \\
\text { Razor [6] } \\
\text { New algorithm }\end{array}$ & $\begin{array}{l}406 \\
251\end{array}$ & $\begin{array}{c}1300^{\mathrm{a}} \\
824\end{array}$ & $\begin{array}{c}1250^{\mathrm{a}} \\
540\end{array}$ \\
\hline
\end{tabular}

Solution not reached with required accuracy.

\section{IMPROVED DESIGN OF INTERDIGITAL FILTERS}

Consider the interdigital filter shown in Fig. 5(a), where $r$ short-circuited lines of equal electrical length $\theta$ are located above a common ground plane. Fig. 5(b) is a crosssectional representation of the filter. The distributed capacitance parameters $C_{i}$ and $C_{i, i+1}$ are defined as follows:

$C_{i} \quad$ capacitance to ground per unit length for the $i$ th conductor;

$C_{i, i+1}$ mutual capacitance per unit length between the $i$ th and the $(i+1)$ th conductors.

Coupling between nonadjacent lines is assumed negligible.

A seven-section Chebyshev bandpass filter having the relative bandwidth $w=0.6$ and $0.1-\mathrm{dB}$ passband ripple is designed using the procedure developed by Pang [21]. It is known that the filter may be chosen symmetrical, thus leaving four self-capacitances and three mutual capacitances to be determined. The impedance level in each

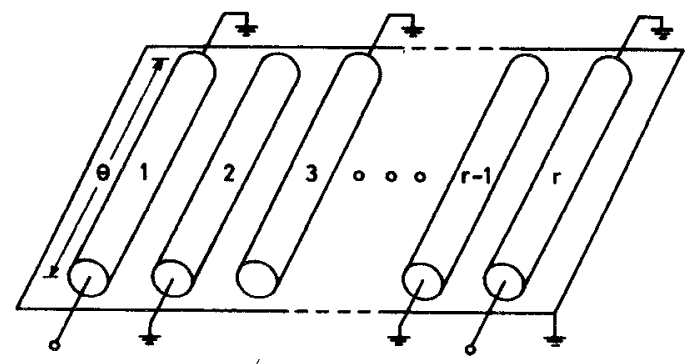

(a)

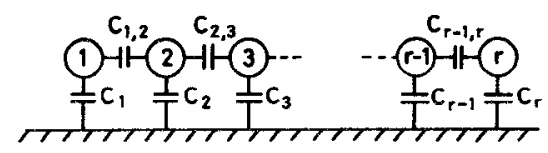

(b)

Fig. 5. (a) Interdigital filter structure. (b) Cross-sectional representation.

interior section of the filter may be varied arbitrarily within the realizability conditions, corresponding to three degrees of freedom in the design. These are utilized to set $C_{r, 2}=C_{2,3}=C_{3,4}$ and $C_{2}=C_{3}$.

The calculated normalized capacitance values are shown in Table III. The parameter $h$ in Pang's design method has been chosen to the value $1 /\left(c_{0}\right)^{1 / 2},{ }^{2}$ where

$$
c_{0}=(\cos (w \cdot \pi / 4)) \text {. }
$$

The computed response of the filter is shown in Fig. 6 . The maximum VSWR in the passband is 1.34.

In order to improve the filter response, an optimization design process is carried out under the following conditions.

1) The capacitance values obtained by the approximate design are used as initial values.

2) The stopband attenuation at $1.0 \mathrm{GHz}$ shall be retained.

3) The three degrees of freedom are utilized to set $C_{1,2}=C_{2,3}=C_{3,4}$ and $C_{2}=C_{3}$, thus leaving only four parameters to be varied.

The problem is to minimize $\max _{j} f_{j}(x)$, where

$$
f_{j}(x)= \begin{cases}P_{j}(x), & \text { in the passband } \\ P_{j}(x)-P_{0}, & \text { in the stopband. }\end{cases}
$$

$P_{0}$ corresponds to the insertion loss at $1.0 \mathrm{GHz}$, and $P_{j}(x)$ is the insertion loss at the $j$ th frequency. Sixty-one uniformly spaced frequencies were selected from the passband, and a single frequency, namely $1.0 \mathrm{GHz}$, from the stopband.

With $\epsilon=10^{-5}$ (Fig. 1), 25 filter response evaluations were necessary in order to obtain convergence. The optimized response is shown in Fig. 6, and the corresponding capacitance values are shown in Table III. As can be seen from Fig. 6, a reduction of the maximum VSWR has been achieved, the maximum value in the passband being 1.29.

\footnotetext{
${ }^{2}$ A private communication with the author has revealed that the optimum choice of the parameter $h$ should read $h=1 /\left(c_{0}\right)^{1 / 2}$ instead of $\left(c_{0}\right)^{1 / 2}$ as stated in the original paper.
} 
TABLE III

\begin{tabular}{|c|c|c|c|c|c|}
\hline$i$ & \multicolumn{2}{|c|}{$\begin{array}{c}C_{i} \cdot R_{g} / \epsilon \\
\text { Pang Optimized }\end{array}$} & $i$ & \multicolumn{2}{|c|}{$\begin{array}{c}C_{i, i+1} \cdot R_{g} / \epsilon \\
\text { Pang Optimized }\end{array}$} \\
\hline $\begin{array}{c}1,7 \\
2,3,5,6 \\
4\end{array}$ & $\begin{array}{l}493.4 \\
778.8 \\
952.5\end{array}$ & $\begin{array}{l}494.6 \\
810.6 \\
954.0\end{array}$ & $1, \cdots, 6$ & 431.6 & 443.0 \\
\hline
\end{tabular}

Note: $R_{g}$ is the generator impedance and $\epsilon$ is the dielectric constant.

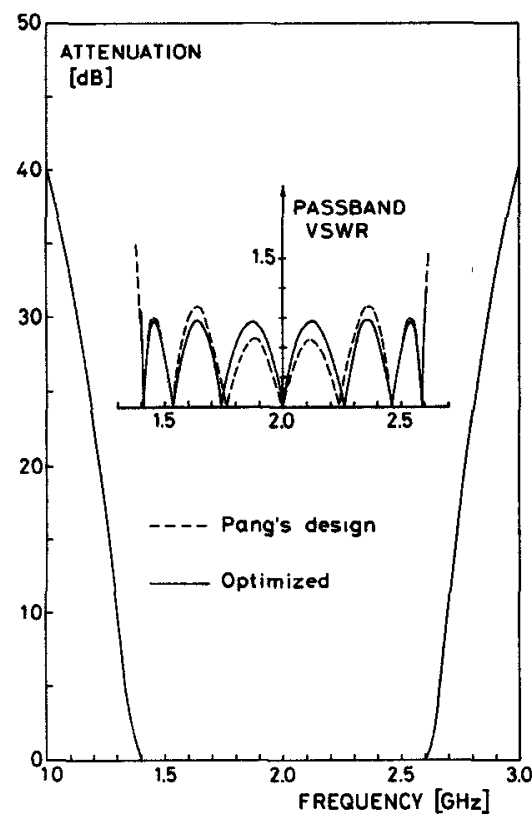

Fig. 6. Computed responses of seven-section interdigital filter.

It is noticed that an exact equiripple response has been obtained. Comparing the capacitance values of the initial and the optimized design, a slight increase of all the values is noticed.

As a future refinement of the optimization, it is foreseen to include the effects of end capacitances so that the computer model more closely will resemble the physical structure of the filter. Taking these and other nonideal effects into account, the design procedure will have been extended beyond the point where any exact analytical method can be applied.

\section{OPTIMUM DESIGN OF MICROWAVE REFLECTION AMPLIFIERS}

Transferred electron devices (TED's) exhibiting a stable broad-band negative resistance may be used in microwave reflection amplifiers [22]. As the negative resistance of the TED is frequency dependent, it is preferable to make use of a computer-aided design approach to achieve a specified amplifier response [23]-[25]. In this section we report on the application of the proposed minimax algorithm in designing a multiple-section coaxial transformer for gain equalization, taking into account step capacitances and losses. The structure under consideration is shown in Fig. 7 (a) and an equivalent diagram in Fig. 7 (b), the dis-

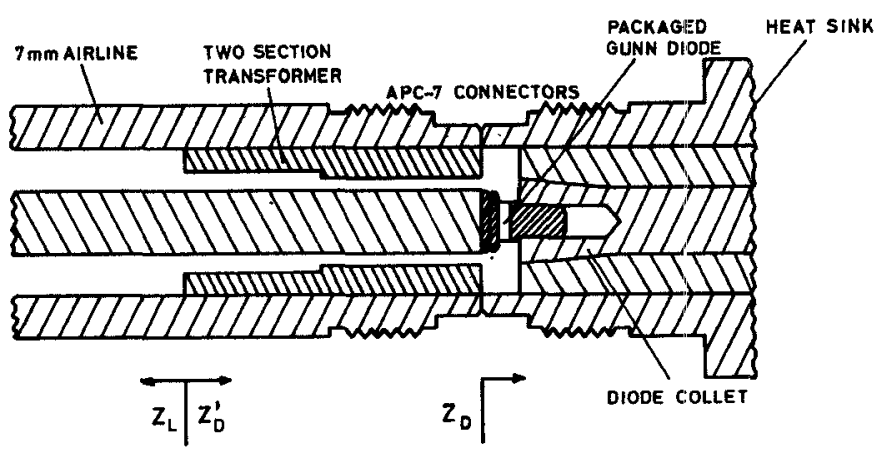

(a)

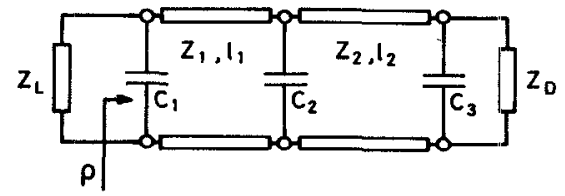

(b)

Fig. 7. Microwave reflection amplifier. (a) Physical structure. (b) Equivalent network.

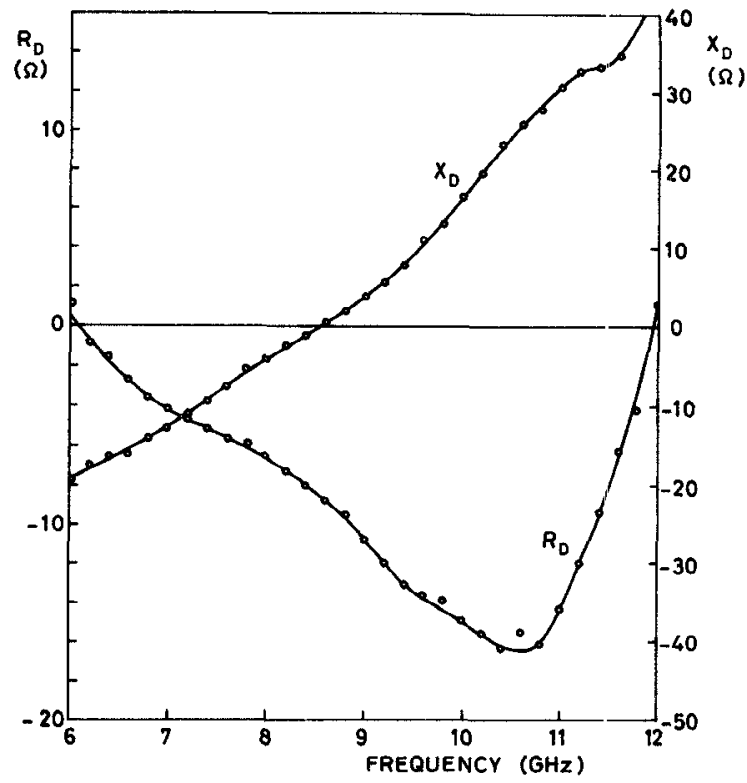

Fig. 8. Measured small-signal impedance $Z_{D}=R_{D}+j X_{D}$ of packaged TED. Device data: $n_{0}=1.5 \cdot 10^{16} \mathrm{~cm}^{-3}, L=12 \mu \mathrm{m}$, $R_{0}=5.6 \Omega, V_{0}=-8.7 \mathrm{~V}$.

continuity capacitances $C_{1}-C_{3}$ being given in [26], [27] The packaged GaAs TED is represented by its measured small-signal impedance $Z_{D}$ (Fig. 8) and the load impedance $Z_{L}$ is also included by measured data exhibiting a VSWR up to 1.4 within the frequency band of interest. In Fig. 9 the experimental setup is sketched, indicating that if a circulator is introduced its frequency characteristic, together with the bias network, may be described by $Z_{L}$. Clearly, this model represents a case where the derivatives would have been obtained by the adjoint network approach only at the expense of considerable numerical efforts.

In a practical design example, the residuals have been defined as 


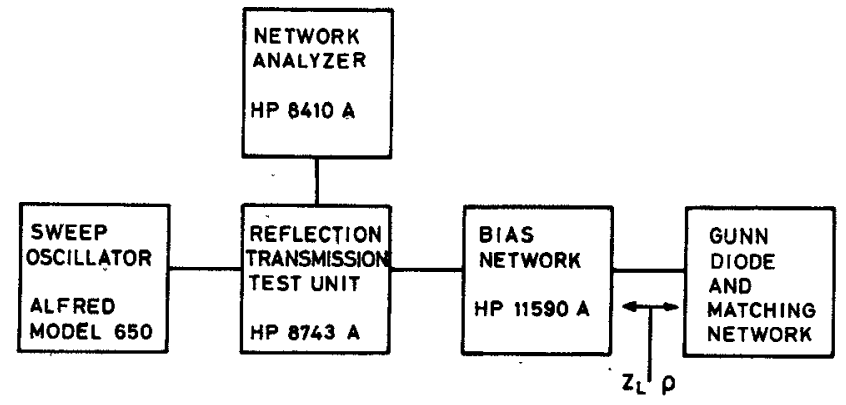

Fig. 9. Experimental setup.

$$
f_{j}(x)=\left|\rho_{j}\right|^{2}-\left|\rho_{0}\right|^{2}
$$

where

$$
\rho_{j}=\frac{Z_{D}{ }^{\prime}-Z_{L}{ }^{*}}{Z_{D}{ }^{\prime}+Z_{L}}, \quad j=1, \cdots, 41
$$

(* denotes complex conjugation), and $\left|\rho_{0}\right|^{2}$ is the specified power gain $(\sim 5 \mathrm{~dB})$ from 7 to $11 \mathrm{GHz}$, the sample frequencies being equidistantly spaced. With the arbitrary starting values $\left(Z_{1}, Z_{2}, l_{1}, l_{2}\right)$ listed in Table IV, convergence was obtained after 61 response evaluations to an accuracy of $\epsilon=10^{-3}$ (Fig. 1). The final parameter values are also found in Table IV. Fig. 10 shows the initial and optimized gain response together with an experimental verification of the optimized amplifier. An excellent agreement with experiments is found. A Nyquist stability check has been performed to ensure that the driving point impedance $Z_{L}+Z_{D}{ }^{\prime}$ does not have any zeros in the right-half complex frequency plane [25].

The results obtained in this section indicate that once a realistic circuit model is established, optimization can easily be carried out to a high degree of accuracy without additional effort in computation of derivatives. Future work in the area of TED reflection amplifiers could be directed towards the application of stable extremely broadbanded devices now being available [28].

\section{CONCLUSION}

A new nongradient minimax optimization algorithm has been developed and implemented. By extensive comparisons with known gradient and nongradient algorithms, it has been established that the new algorithm is superior when solving network design problems for which the adjoint network method is not feasible for gradient computations. This means that the proposed algorithm is particularly relevant to design of microwave networks where parasitics and other nonideal effects are present. Application of the method is straightforward once a circuit model is developed and the results presented for design of interdigital filters and reflection amplifiers demonstrate the reliability and versatility of the method.

\section{ACKNOWLEDGMENT}

The authors wish to thank Dr. B. Jeppsson of the Microwave Institute Foundation, Stockholm, Sweden, for supplying the TED used in the reflection amplifier. They also
TABLE IV

Optimization of TED Reflection AMplifier

\begin{tabular}{lllll}
\hline \hline & $Z_{1}[\Omega]$ & $Z_{2}[\Omega]$ & $l_{1}[\mathrm{~mm}]$ & $l_{2}[\mathrm{~mm}]$ \\
\hline Initial & 36.00 & 23.00 & 8.33 & 8.33 \\
Optimized & 27.20 & 23.65 & 6.48 & 7.70 \\
\hline
\end{tabular}

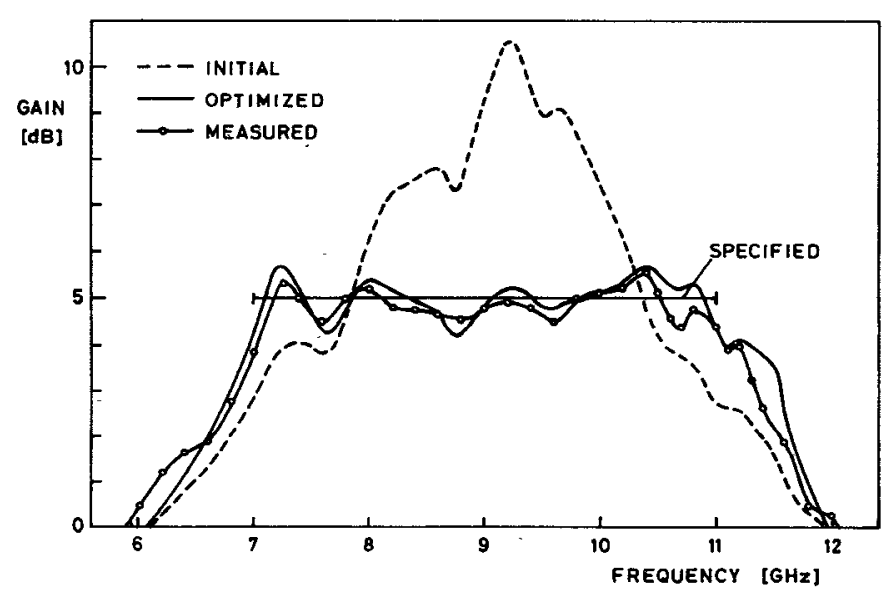

Fig. 10. Frequency responses of broad-band TED reflection amplifier.

wish to thank Mrs. Farida Dahl for her expert typing of the manuscript and Miss Birgitte Holle for making the artwork.

\section{REFERENCES}

[1] I. A. Cermak, W. J. Getsinger, B. W. Leake, A. S. Vander Vorst, and D. Varon, "The status of computer-oriented microwave practices," IEEE Trans. Microwave Theory Tech. (Special Issue on Computer-Orienied Microwave Practices), vol. MTT-22, pp. 155-160, Mar. 1974.

[2] V. A. Monaco and P. Tiberio, "Computer-aided analysis of microwave circuits," IEEE Trans. Microwave Theory Tech. (Special Issue on Computer-Oriented Microwave Practices), vol. MTT-22, pp. 249-263, Mar. 1974.

[3] L. S. Lasdon and A. D. Waren, "Optimal design of filters with bounded, lossy elements," IEEE Trans. Circuit Theory, vol. CT-13, pp. 175-187, June 1966.

[4] F. E. Emery and M. O'Hagan, "Optimal design of matching networks for microwave transistor amplifiers," IEEE Trans. Microwave Theory Tech. (Corresp.), vol. MTT-14, pp. 696-698, Dec. 1966

[5] M. A. Murray-Lasso and E. B. Kozemchak, "Microwave circuit design by digital computer," IEEE Trans. Microwave Theory Tech. (Special Issue on Computer-Oriented Microwave Practices), vol. MTT-17, pp. 514-526, Aug. 1969.

[6] J. W. Bandler and P. A. MacDonald, "Optimization of microwave circuits by razor research" IEEE Trans. Microwave Theory Tech. (Special Issue on Computer-Oriented Microwave Practices), vol. MTT-17, pp. 552-562, Aug. 1969.

[7] T. N. Trick and J. Vlach, "Computer-aided design of broadband amplifiers with complex loads," IEEE Trans. Microwave Theory Tech., vol. MTT-18, pp. 541-547, Sept. 1970.

[8] V. G. Gelnovatch and I. L. Chase, "DEMON-An optimal seeking computer program for the design of microwave circuits," IEEE Trans. Solid-State Circuits (Special ISSCC Issue on Solid-State Microwave Circuits), vol. SC-5, pp. 303-309, Dec. 1970.

[9] S. W. Director and R. A. Rohrer, "Automated network design-The frequency-domain case," IEEE Trans. Circuit Theory, vol. CT-16, pp. 330-337, Aug. 1969.

[10] J. W. Bandler, T. V. Srinivasan, and C. Charalambous, "Minimax optimization of networks by grazor search," IEEE Trans. Microwave Theory Tech., vol. MTT-20, pp. 596-604, Sept. 1972.

[11] J. W. Bandler and C. Charalambous, "Practical least $p$ th optimization of networks," IEE'E Trans. Microwave Theory Tech. (1972 Symposium Issue), vol. MTT-20, pp. 834-840, Dec. 1972

[12] C. Charalambous and J. W. Bandler, "New algorithms for net- 
work optimization," IEEE Trans. Microwave Theory Tech. (1979 Symposium Issue), vol. MTT-21, pp. 815-818, Dec. 1973.

[13] Y. Ishizaki and H. Watanabe, "An iterative Chebyshev approximation method for network design," IEEE Trans. Circuit Theory (Special Issue on Modern Filter Design), vol. CT-15, pp. 326-336, Dec. 1968.

[14] R. Fletcher, "A new approach to variable metric algorithms," Comput. J., vol. 13, pp. 317-322, Aug. 1970.

[15] M. R. Osborne and G. A. Watson, "An algorithm for minimax approximation in the non-linear case," Comput. J., vol. 12, pp. 63-68, Feb. 1969.

[16] K. Madsen, H. Schjær-Jacobsen, and J. Voldby, "Automated minimax design of networks," IEEE Trans. Circuits Syst., vol. CAS-22, pp. 791-796, Oct. 1975.

[17] C. G. Broyden, "A class of methods for solving non-linear simultaneous equations," Math. Comput., vol. 19, pp. 577-593, 1965.

[18] M. J. D. Powell, "A Fortran subroutine for unconstrained minimization, requiring first derivatives of the objective functions," AERE, Harwell, Oxon., England, Rep. R 6469, pp. 1-43, July 1970 .

[19] -The minimax solution of linear equations subject to bounds on the variables," AERE, Harwell, Oxon., England, Rep. C.S.S. 11, Dec. 1974 .

[20] K. Madsen, "Minimax solution of non-linear equations without calculating derivatives," in Mathematical Programming, Studies No. 3, P. Wolfe and M. Balinski, Ed. to be published.
[21] K. K. Pang, "Design of microwave filters by sine-plane approach," IEEE Trans. Microwave Theory Tech., vol. MTT-21, pp. $607-611$. Oct. 1973 .

[22] C. L. Upadhyayula and B. S. Perlman, "Design and performance of transferred electron amplifiers using distributed equalizer networks," IEEE J. Solid-State Circuits (Special Issue on Microwave Integrated Circuits), vol. SC-8, pp. 29-36, Feb. 1973.

[23] R. W. Paglione and B. S. Perlman, "Computerized désign of M/W devices," Microwave J., vol. 16, pp. 23-28, Aug. 1973.

[24] B. S. Perlman and V. G. Gelnovatch, "Computer aided design, simulation and optimization," in Advances in Mirrowaves, vol. 8. New York: Academic, 1974, pp. 321-399.

[25] E. Hammershaimb, P. Jeppesen, and H. Schjær-Jacobsen, "Computer-aided design of broad band reflection type amplifiers," Int. J. Circuit Theory Appl., vol. 2, pp. 261-268, Sept. 1974 .

[26] J. R. Whinnery, H. W. Jamieson, and T. E. Robbins, "Coaxialline discontinuities," Proc. IRE, vol. 32, pp. 695-709, Nov. 1944.

[27] P. I. Somlo, "The computation of coaxial line step capacitances," IEEE Trans. Microwave Theory Tech., vol. MTT-15, pp. 48-53, Jan. 1967.

[28] S. H. Izadpanah, B. Jeppsson, P. Jeppesen, and P. Jøndrup, "Stable amplification and high current drop bisicable switching in supereritical GaAs TEDs," in Proc. 4th European Microwave Conf. (Montreux, Switzerland), Sept. 10-13, 1974, pp. 242-246.

\title{
Microwave Effect on Rabbit Superior Cervical Ganglion
}

\author{
KENNETH R. COURTNEY, JAMES C. LIN, MEMBER, IEEe, ARTHUR W. GUY, SENIOR MEM3er, IEeE, \\ aND CHUNG-KWANG CHOU, STUdent MEMBer, IEEE
}

\begin{abstract}
Rabbit superior cervical ganglia were exposed to $\mathrm{CW}$ 2450-MHz fields within a temperature-controlled waveguide environment. Absorbed power densities between 2 and $1000 \mathrm{~W} / \mathrm{kg}$ failed to significantly influence transmission latencies of responses recorded from postganglionic fibers due to stimulation of either $B$ (myelinated) or $C$ (unmyelinated) fibers in the preganglionic trunk.
\end{abstract}

\section{INTRODUCTION}

$\mathbf{T}$ HERE have been numerous reports on the effects of microwave radiation on the central nervous system (CNS). This can be significant since the nervous system processes the multitudinous information coming in from the periphery and determines the signals to be transmitted back to the different parts of the body to initiate various

Manuscript received October 10, 1974; revised April 7, 1975: This work was supported in part by the Bureau of Radiological Health, Food and Drug Administration under Grant R01-FD-00646 and, in part by the Social and Rehabilitation Services Research and Training Center under Grant 16-P-56818/0-12.

$K$. R. Courtney was with the Department of Rehabilitation Medicine, School of Medicine, University of Washington, Seattle, Wash. 98195. He is now with the University of Colorado Medical Center, Boulder, Colo. 80302.

J. C. Lin was with the Department of Rehabilitation Medicine, School of Medicine, University of Washington, Seattle, Wash. 98195. He is now with the Department of Electrical Engineering, Wayne State University, Detroit, Mich. 48202.

A. W. Guy and C.-K. Chou are with the Department of Rehabilitation Medicine, School of Medicine, University of Washington, Seattle, Wash. 98195. motor activities. Unfortunately, many of these reports have suffered from a lack of procedural details which make the evaluation of the purported findings difficult [1] and others have based their findings on nonspecific changes which only implicate nervous system involvement.

Previous work in this laboratory has shown that during controlled irradiation of the heads of cats, shifts in the latencies and amplitudes of evoked thalamic responses can occur [2]-[4]. However, these changes were evident only in cases where the incident microwave power was sufficient to induce an increase in the thalamic temperatures. Subsequent experimentation with conduction heating via fluid circulating heat exchanges implanted at the base of the skull also corroborated the preceding observations [5]. The complexity of the thalamic preparation, however, seriously limits the interpretation of the observed phenomenon in terms of precise neural involvement. Consequently, a study was initiated where isolated mammalian and amphibian nerves were irradiated in vitro in a Ringer's filled waveguide environment. It was found [6] that the conduction characteristics of these peripheral nerves were not affected by microwave radiation if care was taken to control the temperature surrounding the nervous tissue during microwave exposure. The isolated peripheral nerve functions only as a neural transmission line, however, and these studies do not reveal the sig- 